\title{
População de Rua no Empoderamento do Acesso à Saúde
}

\section{Empowering homeless people ${ }^{1}$ to access Health Care}

DOI: $10.46919 / \operatorname{archv1n5-016}$

Recebimento dos originais: 10/07/2020

Aceitação para publicação: 30/08/2020

\section{Marta Regina Marques Akiyama}

Bacharel em Serviço Social - Universidade Cruzeiro do Sul

Técnica em Terapia Sistêmica Família e Casal, pela Universidade Estadual de São Paulo UNIFESP Ano de 2009

Centro Social Nossa Senhora do Bom Parto - Coordenadora do Consultório na Rua de São Paulo S.P desde 2004.

Rua Sapucaia 413 - Alto da Mooca - CEP 03170-050. - São Paulo S.P

E-mail: marta.saudenarua@gmail.com

\section{RESUMO}

O Consultório Na Rua “ projeto A Gente na Rua”, teve início em outubro de 2004, pioneiro no Brasil e com muitas especificidades, desenvolvendo ações de saúde para pessoas em situação de rua, atualmente modelo de atenção à saúde das pessoas em situação de rua em diversos estados e municípios do Brasil, sendo fundamentado pelo documento nos princípios do SUS, onde se preconiza a integralidade, universalidade e equidade.

O Centro Social Nossa Senhora do Bom Parto e a Secretaria Municipal de Saúde do Município de São Paulo, iniciaram uma estratégia desafiadora e inovadora, fundamentado pelo SUS, estruturando, recuperando e entendendo a heterogeneidade dessas pessoas que se encontram em situação limite de sobrevivência, miséria e baixa estima.

O diferencial deste trabalho se caracteriza pela contratação de pessoas com vivência em situação de rua/albergue, para atuar como agentes de saúde de rua, de forma planejada e continuada envolvendo profissionais de diversas formações, para que o trabalho seja realizado de forma efetiva.

Palavras-chaves: população em situação de rua, resiliência, trabalho e saúde.

\begin{abstract}
he Consultório Na Rua "A Gente na Rua" Project, has starting in October 2004 anos was pioneer in Brazil. With many specificities, developed health actions for homelless people, and has became a model of healthcare of homeless people in many cities in Brazil, based on the principles of SUS (The Health Sistem of the country), which advocates integrality, universality and equity. The Nossa Senhora do Bom Parto Social Center and the Municipal Health Secretary of São Paulo, started a challenging and innovative strategy, based on SUS, structuring, recovering and understanding the heterogeneity of these people who are in a situation of extreme survival, misery and low esteem. The differential of this work is characterized by the hiring of homeless people, to work as health agents, in a planned and continuous way involving professionals from different backgrounds, so that the work is carried out effectively.
\end{abstract}

1 Homeless people is here understood as "Pessoa em situação de rua" (people in street situation), defined by Nacional Policy for Homeless People (PNPSR - Decreto 7.053 / 2009) as an "heterogeneous population group that has in common the extreme poverty, interrupted or weakened family bonds and the lack of regular conventional housing, and which uses public places and degraded areas as living and sustenance spaces, temporarily or permanently, as well as shelter units for overnight stays or as temporary housing." 
Keywords: homeless population, resilience, work and health.

\section{INTRUDUÇÃO}

Em outubro de 2004, teve início o "Projeto A Gente na Rua", atualmente Consultório Na Rua em São Paulo, pioneiro no Brasil e com muitas especificidades, desenvolvendo ações de saúde para pessoas em situação de rua, modelo este compreendido de extrema importância para atenção à saúde das pessoas em situação de rua em diversos Estados e o/Municípios do Brasil. O Consultórios na rua desenvolve ações integrais de saúde frente às necessidades das pessoas em situação de rua. O cuidado acontece de forma itinerante, respeitando o perfil de seu público alvo. Preparado para atuar em toda a cidade de São Paulo e possui uma rede de comunicação eficiente, onde permite a troca de informações entre os profissionais sobre os pacientes de risco em tempo real.

O Programa é baseado no documento norteador construído pelos profissionais que atuam diretamente com as pessoas que vivem em situação de rua, fundamentando nos princípios do SUS de integralidade, universalidade e equidade.

Portanto este norteia toda a estrutura de trabalho que se movimenta em ações amplas, compreendendo as necessidades específicas desta população.

Buscando contextualizar brevemente a história, em 2003, O Grito dos Excluídos é uma luta dos movimentos e lideranças das pessoas em situação em situação de rua, como forma de protestar ou de pedir ajuda diante da necessidade ou de sofrimento desta população.

Em 2003, o tema escolhido foi "O direito à Saúde" abordando as doenças de maior incidência nas pessoas em situação de rua, a exemplo disso, a tuberculose, onde pesquisas apontam que a prevalência pode ser superior a sessenta vezes mais que a população residente, o mesmo em relação a outras comodidades, como, HIV, Sífilis, Hepatite entre outras, a partir daí iniciou algumas reuniões da sociedade civil, movimentos de população de rua e poder público para buscar formas de acolher o clamor desta população altamente vulnerável.

Em 2004, houve o Massacre da Praça da Sé, região central de São Paulo, em que sete pessoas em situação de rua, foram cruelmente assassinadas enquanto dormiam, onde teve destaque da imprensa Brasileira e em outros Países, empenhando ainda mais a necessidade de respostas e junto da Pastoral do Povo da Rua, Centro Social Nossa Senhora do Bom Parto, participaram de um conjunto de estratégias junto da Secretaria Municipal de São Paulo.

As equipes realizam diretamente o atendimento integral da saúde da população de seu território, bem como auxiliam o acesso da mesma nos serviços de especificidades em saúde da região, para um cuidado emergencial ou um seguimento longitudinal. 
Atualmente temos mais de 12.500 pessoas em situação de rua, cadastradas e acompanhadas pelas 25 equipes, no Município de São Paulo.

O diferencial deste trabalho se caracteriza pela contratação de pessoas com vivência em situação de rua/albergue, para atuar como agentes de saúde de rua, de forma planejada e continuada envolvendo profissionais de diversas formações, para que o trabalho seja realizado de forma efetiva.

No cotidiano do trabalho buscamos estabelecer o primeiro cuidado através do vínculo e das relações construídas anteriormente pelos Agentes de Saúde de Rua (ACSR). A presença do Agente de Saúde com a vivencia de rua/equipamento social, passa a ser um facilitador para a equipe multiprofissional, propiciando alcançar uma atenção efetiva e de alta qualidade, capaz de prevenir os agravos à saúde mais prevalentes de cada região.

A partir destas constatações a Equipe técnica constrói com o paciente, elaborar em conjunto o Projeto Terapêutico Singular, onde identificada as necessidades, demandas e projeções futuras individuais se busca estabelecer a curto, médio e longo prazo um Plano de vida alicerçada na realidade e nas possibilidades de cada um.

\section{OBJETIVO}

Garantia do acesso equânime das pessoas em situação de rua a todos os serviços da rede sócio assistencial de saúde e assistência social, entre outras políticas sociais, com igualdade de direitos;

Construção de alternativas de superação da realidade atual em que os pacientes se encontram, oferendo suporte e auxilio ao seu Projeto de vida através do desenvolvimento da resiliência.

Pessoas em Situação de rua - destacamos que com a implantação do Programa ao serem admitidas com contrato formal de trabalho muitas oportunidades e acessos de bens e serviços se tornaram possíveis através de apoio institucional e parcerias, para apoio na inserção de cursos universitários e bens duráveis.

\section{CONCLUSÃO}

Dados - alguns números que nos fazem acreditar que o trabalho desenvolvido tem tido excelentes resultados, após 15 anos de existência:

$75 \%$ dos ASR saíram das ruas e hoje moram por conta própria;

18\% ASR ingressaram na Faculdade;

95\% retomaram contato com a família;

$70 \%$ voltaram a estudar /curso;

$75 \%$ retomaram seus projetos de vida. 
Em 16 anos de trabalho, já podemos identificar através dos resultados contundentes a promoção e/ou fomento de resiliência, além do olhar do profissional que é essencial para tornar a ação legitima.

O território é retratado enquanto o chão das políticas sociais e visto além do olhar geográfico. Para uma melhor compreensão do fenômeno população em situação de rua é necessário apreender as múltiplas determinações que constituem essa situação, bem como acompanhar o movimento histórico, político e econômico social da realidade que está em constante transformação.

Os agentes de saúde, apoiado pelos profissionais da equipe e instituição, por meio de seu trabalho, tornam se capazes de intervenções e reflexões societárias, como a discussão do uso do espaço público, produções artísticas e culturais, dando visibilidade às grandes injustiças sociais entre outros. Sendo assim, a equipes vão além da Saúde, trazendo novas formas de cuidar, as ações e os diferentes serviços de saúde e são articulados a partir das demandas e necessidades individuais e coletivas, considerando o território que habitam nas ruas e os recursos potentes nele existente.

A nossa proposta vai além do cuidado com a pessoa em situação de rua/ agente de saúde e saúde mental, engloba o atendimento à gestante de rua, tratamento de patologias pulmonares (a tuberculose é frequente), tratamento de doenças sexualmente transmissíveis (HIV/AIDS), tratamento de doenças de pele (úlceras de membros inferiores), problemas ortopédicos (decorrentes de situação de violência, atropelamento), diabetes, hipertensão, e várias outras situações que ficam sob a responsabilidade da estratégia saúde da família na atual política de atenção básica.

Dessa forma, entendemos que a inserção das pessoas em situação de rua, voltadas ao cuidado no escopo das ações da atenção básica representa uma ampliação no sentido de efetivar os direitos à saúde desta população., no cuidado longitudinal.

Vimos que os agentes de saúde são pessoas resilientes e que eles foram capazes de superar os obstáculos e as adversidades de suas vidas, e hoje vivem e trabalham para fomentar este mesmo sentimento de luta naqueles que passam as mesmas dificuldades pela qual eles passaram.

Os agentes apresentam uma tendência a se tornarem pessoas mais flexíveis, otimistas, criativas e intuitivas, valendo-se da vivência adquirida nas mesmas condições que hoje tratam. Em relação a equipe técnica, é possível afirmar que adquirimos a capacidade de ação que potencializou o crescimento da rede de atenção e vem resultando na melhoria do acesso a cada dia.

Concluímos que a consciência da importância dos fatores de proteção/risco está proporcionalmente ligada à resposta de sua ação para um processo de transformação.

Os agentes são empoderados e promovem esta mesma inclusão, econômica e política, independentemente da idade, gênero, deficiência, raça, etnia, origem, religião, a reconstrução da sua autoimagem e identidades são cada vez mais positivas, elevando sua autoestima, estimulando o surgindo 
cada vez mais a consciência crítica sobre sua condição anterior e, consequentemente, a reivindicação de direitos.

Atualmente temos muitas transexuais, gays e hetero todos com os mesmos direitos e promovendo a inclusão aos demais colegas, construindo projetos de vida que anteriormente não era mensurado, incluindo possibilidade não apenas de saída das ruas, mas de fomentar este mesmo sentimento em quem ainda se encontra nesta situação.

O Bompar acredita que o sucesso dos Consultórios na Rua se deve à competência e insistência dos profissionais em construir formas diferenciadas de cuidar das pessoas em situação de rua como igual e ainda que haja desafios institucionais, humanos e técnicos a serem superados.

O olhar "despreconceituado" é um dos pilares do trabalho do Consultório na Rua/Bompar, somente conseguimos acolher o outro se nos despirmos de quaisquer julgamentos e ideias que possamos ter ou pré-estabelecer. Por isso o consultório na rua faz a diferença na vida dos atendidos. 